\title{
Avaliação da inflamação de vias aéreas em asmáticos após o teste de broncoprovocação com metacolina*
}

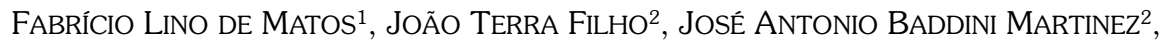 \\ TATIANA FuRlan SAla ${ }^{3}$, Elcio OliVEIRA VianNA ${ }^{2}$
}

Introdução: O teste de broncoprovocação com metacolina é comumente empregado em pneumologia para medir a reatividade brônquica com finalidade de diagnóstico ou acompanhamento

da asma. Objetivo: Pesquisar efeitos tardios da inalação de metacolina na inflamação brônquica avaliada pelo escarro induzido. Casuística e métodos: Foram selecionados dez pacientes com asma leve ou moderada, não tabagistas, com medicação e quadro clínico estáveis. Às 12:00h, os pacientes receberam inalação, aleatoriamente designada, de metacolina (broncoprovocação) ou soro fisiológico.

Às 18:00h, foi realizada a indução de escarro. Em outro dia, com intervalo de uma semana, os pacientes completaram o protocolo, recebendo a outra inalação (metacolina ou soro fisiológico) $e$ nova indução de escarro. Resultados: Após metacolina, obtiveram-se 8,6 $\pm 9 \mathrm{~g}$ de escarro, 8,6 6 6

milhões de células, sendo $78 \pm 10 \%$ viáveis e $6,8 \pm 7 \%$ eosinófilos. Esses dados não foram significativamente diferentes dos resultados obtidos após soro fisiológico: escarro $=7,6 \pm 6 \mathrm{~g}$, células $=$ $12,4 \pm 12$ milhões, $82 \pm 10 \%$ viáveis e 6,6 $\pm 9 \%$ eosinófilos. A queda de pico de fluxo observada durante a indução de escarro também não diferiu: $21,4 \pm 12 \%$ após metacolina e $18,4 \pm 15 \%$ após soro fisiológico. A queda de pico de fluxo durante a indução correlacionou-se com a quantidade de escarro ( $p=0,018)$ e percentagem de eosinófilos $(p=0,003)$. Outras correlações entre parâmetros

funcionais e do escarro não foram significantes. Conclusão: O teste de broncoprovocação com metacolina realizado seis horas antes da indução de escarro não altera significativamente a quantidade e nem a constituição celular do escarro. (J Pneumol 2001;27(4):171-176)

\section{Airway inflammation in asthmatic patients after methacholine challenge}

Background: The methacholine challenge test is commonly used to evaluate bronchial responsiveness in diagnosis and follow-up of asthmatic patients. Objective: To investigate late effects of methacholine challenge on induced sputum. Methods: Ten non-smoker patients with mild or moderate stable asthma were recruited. At 12:00 p.m., patients were randomly assigned to inhale either methacholine (challenge) or physiologic saline. At 6:00 p.m., sputum induction was performed. On the second visit, one week apart, patients completed their participation in the study by undergoing another inhalation and sputum induction. Results: After methacholine, 8.6 $\pm 9 \mathrm{~g}$ of sputum were expectorated with $8.6 \pm 6$ million cells, $78 \pm 10 \%$ were viable, and $6.8 \pm$ $7 \%$ eosinophils. These data were not different from results obtained after saline: sputum amount $=7.6 \pm 6 \mathrm{~g}$, total cell count $=12.4 \pm 12$ million, viability $=82 \pm 10 \%$, and eosinophils $=6.6 \pm$ 9\%. Expiratory flow (PF) peak fall during sputum induction was not different: $21.4 \pm 12 \%$ after methacholine and $18.4 \pm 15 \%$ after saline. The PF fall observed during induction correlated with

* Trabalho realizado na Divisão de Pneumologia do Departamento de Clínica Médica da Faculdade de Medicina de Ribeirão Preto - Universidade de São Paulo (FMRP-USP). Esse trabalho foi financiado pela Fundação de Amparo à Pesquisa do Estado de São Paulo Fapesp, processos 98/10382-6 e 99/07184-0.

1. Aluno do Curso de Medicina e Bolsista Fapesp (iniciação científica).

2. Doutor em Pneumologia e Docente do Departamento de Clínica Médica.
3. Médica Pneumologista e Pós-graduanda do Departamento de Clínica Médica.

Endereço para correspondência - Dr. Elcio O. Vianna, Depto. de Clínica Médica, Hospital das Clínicas de Ribeirão Preto, Av. Bandeirantes, 3.900 - 14048-900 - Ribeirão Preto, SP. Tel. (16) 602-2706; Fax (16) 633-6695; E-mail: evianna@uol.com.br

Recebido para publicação em 9/1/01. Aprovado, após revisão, em 30/3/01. 
the amount of expectorated sputum $(p=0.018)$ and eosinophil relative number $(p=0.003)$. No other significant correlation between lung function measurements and sputum characteristics was found. Conclusion: A methacholine challenge carried out six hours before sputum induction does not significantly alter the cellular constituents or amount of sputum.

Descritores - Asma. Cloreto de metacolina. Testes de provocação brônquica.

Key words - Asthma. Methacholine chloride. Bronchial provocation tests.

\section{INTRODUÇÃO}

A broncoprovocação com metacolina é um método diagnóstico e científico para a medida da reatividade brônquica. O achado de aumento da reatividade brônquica é determinante para o diagnóstico clínico em diversas situações e é utilizado como parâmetro para medir respostas terapêuticas na asma. A exclusão do diagnóstico de hiper-reatividade brônquica, através de resposta normal à inalação de metacolina, é também importante na prática clínica e científica, porque nos auxilia a descartar o diagnóstico de asma ${ }^{(1)}$. Paralelamente à avaliação da reatividade brônquica, a análise da inflamação de vias aéreas oferece informações complementares e valiosas. Um possivel efeito da inalação de metacolina nos parâmetros inflamatórios do asmático poderia interferir em estudos ou situações em que a avaliação da inflamação seja necessária. Além do mais, se a metacolina tiver efeito de intensificar a inflamação, a broncoprovocação tornar-se-á teste de maior risco. Poucos estudos têm-se dedicado a esses aspectos da broncoprovocação com metacolina.

$\mathrm{O}$ escarro induzido, recentemente aprimorado, tem-se tornado um instrumento de avaliação da inflamação de vias aéreas em asmáticos cada vez mais empregado(2). $\mathrm{O}$ procedimento é mais seguro do que a broncoscopia $e$ pode avaliar diversos parâmetros inflamatórios, principalmente, para fins de investigação científica da asma. A indução do escarro é um procedimento não invasivo que se faz pela inalação de solução hipertônica (como $\mathrm{NaCl}$ a $4,5 \%$ ) por tempo determinado, dez a 20 minutos, para provocar a secreção brônquica e, portanto, a expectoração, possibilitando o estudo de material oriundo das vias aéreas. Não se processa o escarro induzido como em laboratórios gerais, através de simples esfregaço do material, mas sim através da lise do muco do escarro, que o transforma em estado líquido, como é o lavado broncoalveolar (LBA), o líquido pleural, líquido ascítico, etc. Só assim é possivel separar as células e sobrenadante, realizar a contagem do número total de células, analisar o sobre-
Siglas e abreviaturas utilizadas neste trabalho

LBA - Lavado broncoalveolar

$\mathrm{VEF}_{1}$ - Volume expiratório forçado no primeiro segundo

PC20 - Concentração de metacolina provocadora de queda de $20 \%$ do $\mathrm{VEF}_{1}$

$\mathrm{PF}-\mathrm{Pico}$ de fluxo

nadante e preparar lâminas para diversos fins citológicos ou imunocitológicos.

Com o objetivo de pesquisar efeitos pró-inflamatórios da metacolina e, portanto, caracterizar melhor o teste de broncoprovocação com metacolina, avaliamos o escarro induzido seis horas após a inalação de metacolina comparando-o com o escarro colhido seis horas após a inalação de soro fisiológico. O estudo foi realizado em pacientes com asma leve ou moderada, no período intercrise.

\section{MATERIAL E MÉTODOS}

\section{Casuística}

Foram selecionados pacientes do Hospital das Clínicas da Faculdade de Medicina de Ribeirão Preto que apresentavam asma leve ou moderada definidas conforme a publicação Guidelines for the Diagnosis and Management of Asthma - 1997 (National Asthma Education and Prevention Program - USA)(3). Portanto, era requisito o diagnóstico de asma baseado na presença de obstrução de vias aéreas com reversibilidade parcial ou total, de sintomas episódicos relacionados à obstrução e na ausência de outros diagnósticos. Para completar os critérios de seleção, o volume expiratório forçado no primeiro segundo $\left(\mathrm{VEF}_{1}\right)$ deveria ser igual a ou maior que $60 \%$ do valor previsto, a idade entre 18 e 60 anos, quadro clínico estável e capacidade de compreender e executar os procedimentos envolvidos no estudo. Foram excluídos tabagistas, portadores de doenças pulmonares além de asma e pacientes em uso de antibióticos ou corticosteróides sistêmicos. Pacientes que haviam apresentado infecção respiratória nas seis semanas precedendo o estudo tiveram sua participação adiada.

\section{Aspectos éticos}

Os pacientes que preencheram os critérios para seleção receberam informações sobre os objetivos do estudo, 
procedimentos envolvidos e riscos. Se voluntários, assinaram um termo de consentimento livre e esclarecido. $\mathrm{O}$ estudo foi aprovado pelo Comitê de Ética em Pesquisa do Hospital das Clínicas da Faculdade de Medicina de Ribeirão Preto.

\section{Delineamento do estudo}

O trabalho deu-se em duas consultas, com um intervalo de uma semana entre elas. Em ambas as consultas, os pacientes submeteram-se a uma inalação - em uma, de soro fisiológico, e, na outra, de metacolina (teste de broncoprovocação) - sempre às 12:00h. Os pacientes foram aleatoriamente designados para submeter-se à inalação de metacolina na primeira ou na segunda consulta. No dia de cada consulta, eles retornaram ao laboratório de função pulmonar às 18:00h para indução de escarro.

\section{Broncoprovocação com metacolina}

O teste de broncoprovocação com metacolina foi realizado empregando-se cloreto de metacolina (Sigma, St. Louis, MO, EUA) diluído em solução salina tamponada (PBS), de acordo com padronização usada em nosso laboratório ${ }^{(4)}$. Resumidamente, concentrações progressivamente maiores (cada uma sendo o dobro da anterior), de 0,03 até $16 \mathrm{mg} / \mathrm{ml}$, foram inaladas com auxílio de um nebulizador (Narco Service, Brasil), cujo débito confirmado era de $0,13 \mathrm{ml} / \mathrm{min}$. As inalações prosseguiram até que queda de pelo menos $20 \%$ do $\mathrm{VEF}_{1}$ fosse detectada. Uma curva dose-resposta foi elaborada e a concentração necessária para provocar queda de $20 \%$ no $\mathrm{VEF}_{1}(\mathrm{PC} 20)$ foi calculada.

\section{Indução e análise do escarro}

Antes da indução, realizamos medida do pico de fluxo

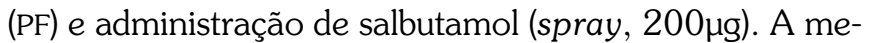
dida do PF foi repetida a cada cinco minutos durante a indução do escarro, que se constituiu de inalação de solução salina hipertônica $(4,5 \%)$ com 20 minutos de duração. Utilizamos um nebulizador ultra-sônico (UltraNeb 2000, DeVilbiss, Somerset, PA, EUA) que gera partículas com tamanho médio de $4,5 \mu$ e débito de $2,5 \mathrm{ml} / \mathrm{min}$. Mesmo que tivessem que interromper a inalação, os pacientes foram orientados a tossir quando necessário $e$ a escarrar em um frasco plástico, sendo a saliva desprezada previamente. Se ocorressem sintomas intensos (chiado, tosse ou dispnéia), o procedimento seria interrompido e cancelado, assim como se houvesse queda de função pulmonar maior que ou igual a $20 \%{ }^{(5)}$. Para a análise, o escarro foi misturado e homogeneizado a ditiotreitol (DTT). O número e viabilidade celulares foram avaliados em hemocitômetro (câmara de Neubauer) após coloração com azul de Trypan. Lâminas para contagem diferencial foram preparadas por citocentrifugação e coloração com May-Grunwald-Giemsa.

\section{Análise estatística}

Após a confirmação da distribuição normal, o teste $t$ pareado bicaudado de Student foi usado para a comparação entre as duas situações (após metacolina e após soro fisiológico). Calculamos o coeficiente de correlação de Pearson, designado r, para pesquisar a correlação entre os parâmetros funcionais e do escarro. Foi considerado significante o valor de $\mathrm{p}<0,05$. Os dados estão expostos como média \pm desvio padrão.

\section{RESULTADOS}

As características gerais dos pacientes estão demonstradas na Tabela 1, onde também se vêem os resultados da queda do PF causada pela indução de escarro. Os valores da queda do PF durante a indução ultrapassaram, em alguns casos, o limite predeterminado por duas razões: primeira, porque, quando detectada, a queda de PF já havia ultrapassado $20 \%$. E, segunda, porque nos asseguramos de que ambas as induções, num mesmo paciente, tivessem a mesma duração, mesmo que o PF atingisse o limite estipulado. Isso para evitar que a duração da inalação fosse um fator de interferência na quantidade e celularidade do escarro. Apesar de a queda de PF observada na primeira indução não ter sido, em alguns pacientes, igual à verificada na segunda indução, quando analisamos o grupo todo não detectamos diferença significativa. Isto é, a queda de PF observada na indução após inalação de metacolina foi de 21,4 $\pm 12 \%$ e, após soro fisiológico, de $18,4 \pm 15 \%$ (Tabela 2). Todos os pacientes foram observados e medicados após o procedimento e o broncoespasmo foi revertido rapidamente (menos de 30 minutos) em todos os casos. Não houve sintomas graves ou outras complicações da indução de escarro.

$\mathrm{Na}$ Tabela 2, estão relacionados os resultados dos seguintes parâmetros: PF antes da indução, queda do PF durante a indução, quantidade de escarro induzido, total de células (leucócitos) no escarro colhido, viabilidade celular e percentagem de eosinófilos do escarro colhido seis horas após inalação de soro fisiológico comparados com os parâmetros do escarro colhido seis horas após a inala-

TABELA 1

Características gerais dos pacientes estudados $(n=10)$

$\begin{array}{lc}\text { Idade (anos) } & 41,5( \pm 15,6) \\ \text { Sexo }(\% \text { masculino }) & 80 \\ \text { VEF }_{1}(\% \text { do predito) } & 92,8( \pm 18,2) \\ \text { PC20 }(\mathrm{mg} / \mathrm{ml}) & 1,91( \pm 1,6) \\ \text { Queda do PF na indução }(\%) & 19,9( \pm 13,9)\end{array}$

Dados apresentados como média ( \pm desvio padrão)

$\mathrm{VEF}_{1}$ : volume expiratório forçado no primeiro segundo

PC20: concentração de metacolina provocadora de queda de $20 \%$ do VEF,

PF: pico de fluxo; o valor de queda do PF refere-se às 20 induções de escarro realizadas. 
TABELA 2

Dados da indução e do escarro seis horas após inalação de soro fisiológico ou metacolina

\begin{tabular}{lccc}
\hline & Após soro fisiológico & Após metacolina & p (teste $\boldsymbol{t}$ pareado) \\
\hline PF pré-indução (L/min) & $436( \pm 92)$ & $471( \pm 85)$ & $\mathrm{p}=0,18$ \\
Queda do PF na indução (\%) & $18,4( \pm 15)$ & $21,4( \pm 12)$ & $\mathrm{p}=0,46$ \\
Quantidade de escarro $(\mathrm{g})$ & $7,6( \pm 6)$ & $8,6( \pm 9)$ & $\mathrm{p}=0,39$ \\
Total de células $\left(\times 10^{6}\right)$ & $12,4( \pm 12)$ & $8,6( \pm 6)$ & $\mathrm{p}=0,28$ \\
Viabilidade celular $(\%)$ & $82( \pm 10)$ & $78( \pm 10)$ & $\mathrm{p}=0,23$ \\
Eosinófilos $(\%)$ & $6,6( \pm 9)$ & $6,8( \pm 7)$ & $\mathrm{p}=0,86$ \\
\hline
\end{tabular}

Dados apresentados como média ( \pm desvio padrão)

PF: pico de fluxo

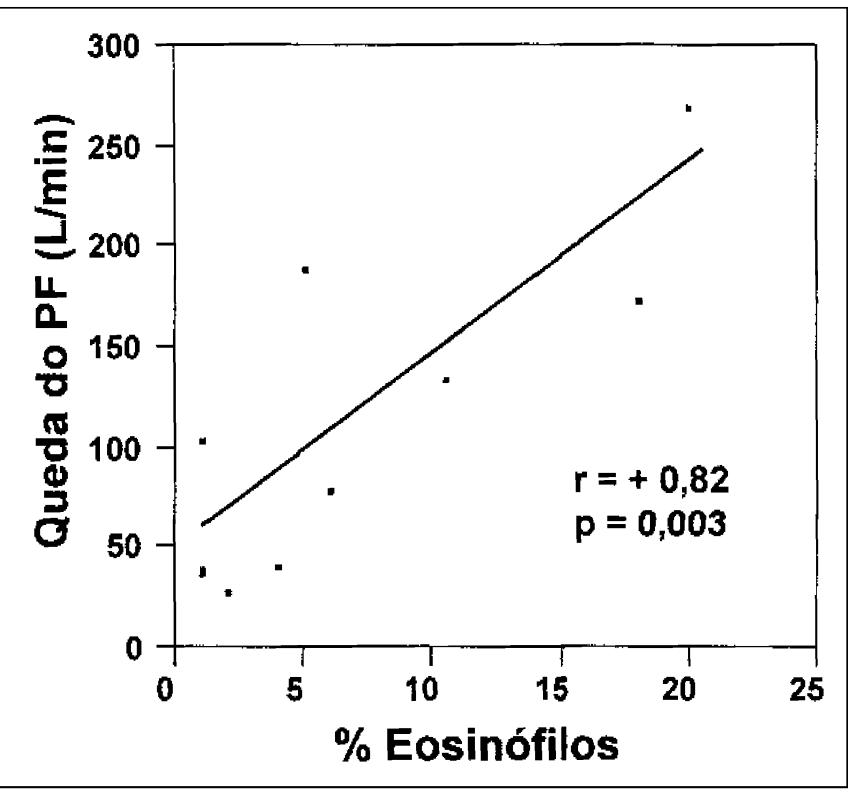

Figura 1 - Há correlação linear positiva entre percentagem de eosinófilos no escarro induzido e queda do pico de fluxo (PF) durante a indução de escarro. Foi utilizado o método de regressão linear simples para a reta demonstrada no gráfico.

ção com metacolina. Através da indução de escarro, após a broncoprovocação com metacolina, obtiveram-se 8,6 $\pm 9 \mathrm{~g}$ de escarro com 8,6 \pm 6 milhões de células, sendo $78 \pm 10 \%$ viáveis e $6,8 \pm 7 \%$ eosinófilos. Esses dados não foram significativamente diferentes dos resultados obtidos após inalação de soro fisiológico (Tabela 2).

A quantidade de escarro correlacionou-se significativamente com a queda do PF, com valor de $\mathrm{r}=+0,72(\mathrm{p}=$ 0,018 ), demonstrando que a maior queda de PF se associava a maior volume de escarro expectorado. Houve também correlação significativa entre a percentagem de eosinófilos no escarro e a queda de PF durante a indução pós-metacolina com $r=+0,82(p=0,003)$ (Figura 1). Entretanto, a queda de PF não se correlacionou com o número total de células no escarro e nem com a viabilida- de destas células. Esses parâmetros do escarro (quantidade, número de células, eosinófilos e viabilidade celular) não se correlacionaram com nenhum dos outros dados funcionais $\left(\mathrm{VEF}_{1}, \mathrm{PC} 20\right.$ ou PF pré-indução) (Tabela 3).

\section{DisCUSSÃO}

Este estudo em pacientes asmáticos demonstrou que o teste de broncoprovocação com metacolina realizado seis horas antes da indução de escarro não altera significativamente seu volume e nem sua constituição celular. Além disso, o risco principal do procedimento de indução de escarro, que é o broncoespasmo, também não se modificou. Com relação a essa queda de função pulmonar durante a indução de escarro, o trabalho permitiu demonstrar que, quanto maior o broncoespasmo durante a indução, maior é a quantidade de escarro produzida e maior a percentagem de eosinófilos nesse escarro, provavelmente, refletindo a maior gravidade da asma.

Conhecer os efeitos tardios das broncoprovocações é fundamental para o pneumologista que executa esses testes. Embora tenhamos demonstrado que a broncoprovocação com metacolina não induz inflamação brônquica em asmáticos, a broncoprovocação com alérgeno certamente o faz. Diaz et al. detectaram que a quantidade de linfócitos, neutrófilos, eosinófilos, proteína básica principal dos eosinófilos e neurotoxina derivada dos eosinófilos no LBA de asmáticos aumenta seis horas após o teste de broncoprovocação com alérgenos ${ }^{(6)}$. O teste de broncoprovocação com a metacolina é indubitavelmente o mais empregado na prática clínica e, portanto, conhecê-lo bem é uma necessidade para os clínicos e pesquisadores dessa área.

Os efeitos do teste de broncoprovocação com metacolina sobre o LBA têm sido mais estudados do que sobre o escarro induzido. Lam et al. demonstraram que a inalação de metacolina realizada dez minutos antes do LBA não modifica a contagem celular deste fluído(7). De modo similar, Soderberg et al. avaliaram a contagem celular e a concentração de albumina no LBA colhido 24 horas após 
TABELA 3

Correlações de Pearson entre dados funcionais e do escarro induzido

\begin{tabular}{|c|c|c|c|}
\hline Parâmetros de função pulmonar & Parâmetros do escarro induzido & $\mathbf{r}$ & $\mathbf{p}$ \\
\hline$\dot{\mathrm{V}} \mathrm{EF}_{1}(\%$ predito $)$ & Quantidade de escarro (g) & $-0,32$ & 0,36 \\
\hline PC20 $(\mathrm{mg} / \mathrm{ml})$ & Quantidade de escarro (g) & $-0,38$ & 0,27 \\
\hline Queda do PF na indução (L/min) & Quantidade de escarro (g) & $+0,72$ & 0,018 \\
\hline$\dot{\mathrm{v}} \mathrm{EF}_{1}(\%$ predito $)$ & Total de células $\left(\times 10^{6}\right)$ & $-0,22$ & 0,54 \\
\hline PC20 $(\mathrm{mg} / \mathrm{ml})$ & Total de células $\left(\times 10^{6}\right)$ & $-0,39$ & 0,25 \\
\hline Queda do PF na indução (L/min) & Total de células $\left(x 10^{6}\right)$ & $+0,59$ & 0,07 \\
\hline$\dot{\mathrm{V}} \mathrm{EF}_{1}(\%$ predito $)$ & Eosinófilos (\%) & $-0,09$ & 0,79 \\
\hline PC20 (mg/ml) & Eosinófilos (\%) & 0 & 1 \\
\hline Queda do PF na indução (L/min) & Eosinófilos (\%) & $+0,82$ & 0,003 \\
\hline
\end{tabular}

a broncoprovocação e nenhuma mudança significante foi detectada ${ }^{(8)}$. Poucos autores encontraram alterações no LBA após broncoprovocação com metacolina e, mesmo assim, essas alterações foram discretas ${ }^{(9)}$. Embora os resultados do LBA e do escarro induzido não possam ser diretamente comparados, os aqui demonstrados confirmam dados prévios de que a inalação de metacolina não leva a mudanças significantes na avaliação da inflamação de asmáticos.

A metacolina é um derivado sintético do neurotransmissor acetilcolina, substância que ocorre naturalmente no organismo. A metacolina é metabolizada mais lentamente pela colinesterase do que a acetilcolina. Seus efeitos podem ser bloqueados ou diminuídos pela atropina $e$ outros agentes anticolinégicos (ex.: brometo de ipratrópio). A metacolina e a histamina causam broncoconstrição em doses aproximadamente equivalentes. A metacolina é preferivel para a medida de reatividade brônquica porque o uso de histamina se associa a mais efeitos colaterais, incluindo cefaléia, rubor cutâneo e rouquidão. Além do que, as medidas com histamina são menos reprodutíveis ${ }^{(1)}$. Além da conhecida ação da metacolina no músculo liso brônquico, foram identificados receptores muscarínicos para a acetilcolina (e, portanto, para metacolina) em células endoteliais, epiteliais, neutrófilos, linfócitos, mastócitos, monócitos e macrófagos ${ }^{(10)}$, o que poderia sugerir um papel pró-inflamatório da metacolina empregada na broncoprovocação. Porém, esse papel não se confirmou neste estudo e nem em trabalhos prévios.

Apesar de a presente casuística não ser muito grande, o aumento do número de pacientes não levaria, provavelmente, a conclusões diferentes. Outra limitação potencial do estudo foi a variabilidade (entre indivíduos) da celularidade total do escarro. Essa variabilidade explicase pela própria abrangência da população estudada, uma vez que tanto pacientes com asma leve como pacientes com asma moderada foram incluídos. A quantidade de escarro e de células depende do tempo de indução. $\mathrm{O}$ tempo de indução foi padronizado, mas foi abreviado no caso de queda de PF intensa. Mesmo assim, certificávamo-nos de que o tempo de indução fosse sempre igual para um mesmo indivíduo. Enfim, estudos futuros utilizando uma população maior e limitada à asma leve trarão resultados interessantes para confirmar estes achados e analisar diferentes tempos após a broncoprovocação e diferentes parâmetros inflamatórios.

Em conclusão, segundo dados da literatura médica, a metacolina é uma boa opção como agente broncoprovocador para a medida de reatividade brônquica e, conforme demonstramos, a administração de metacolina é segura por não induzir alterações celulares tardias. Estudos prévios e os resultados apresentados sugerem que o efeito da metacolina limita-se à contração da musculatura lisa brônquica, apesar de que novos estudos serão necessários para avaliar outros parâmetros do processo inflamatório. Esses resultados auxiliam também o delineamento de pesquisas envolvendo asmáticos, em que a reatividade brônquica à metacolina é medida em tempos próximos aos da avaliação da inflamação de vias áreas.

\section{AgradeCIMENTOS}

Agradecemos à Srta. Elizabet Sobrani e à Srta. Luciana Straccia pela valiosa participação na realização dos testes de broncoprovocação e à Sra. Cristina de Almeida Souza pelo auxílio no processamento do escarro.

\section{REFERÊNCIAS}

1. American Thoracic Society. Guidelines for methacholine and exercise challenge testing - 1999. Am J Respir Crit Care Med 2000;161:309329. 
2. Pizzichini E, Pizzichini MMM, Efthimiadis A, et al. Indices of airway inflammation in induced sputum: reproducibility and validity of cell and fluid phase measurement. Am J Respir Crit Care Med 1996;154:308317.

3. National Asthma Education and Prevention Program. Expert Panel Report 2: Guidelines for the diagnosis and management of asthma. Washington: U.S. Government Printing Office, DC, 1997 (Publication, 97-4051).

4. Cockcroft DW, Killian DN, Mellon JA, Hargreave FE. Bronchial reactivity to inhaled histamine: a method and a clinical survey. Clin Allergy 1977; 7:235-243.

5. Fuente PT, Romagnoli M, Godard P, Bousquet J, Chanez P. Safety of inducing sputum in patients with asthma of varying severity. Am J Respir Crit Care Med 1998;157:1127-1130.

6. Diaz P, Gonzalez MC, Galleguillos FR, Ancic P, Cromwell O, Shepherd $\mathrm{D}$, et al. Leukocytes and mediators in bronchoalveolar lavage during allergen-induced late-phase asthmatic reactions. Am Rev Respir Dis 1989;139:1383-1389.

7. Lam S, Al-Majed S, Chan H, Tse K, LeRiche JC, Chan-Yeung M. Differences in mediator release between allergic rhinitis and asthma. J Allergy Clin Immunol 1991;87:842-849.

8. Soderberg M, Lundgren R, Bjermer L, Angstrom T. Inhaled methacholine does not influence the cellular composition of bronchoalveolar lavage. Allergy 1993;48:173-176.

9. Beasley R, Roche WR, Roberts JA, Holgate ST. Cellular events in the bronchi in mild asthma and after bronchial provocation. Am Rev Respir Dis 1989;139:806-817.

10. Kraft M, Bettinger CM, Wenzel SE, Irvin CG, Ackerman SJ, Martin RJ. Methacholine challenge does not affect bronchoalveolar fluid cell number and many indices of cell function in asthma. Eur Respir J 1995; 8:1966-1971 